\title{
The Winner's Events in the Bangkok Asian Games: The Sponsorship Analysis of Samsung Electronics 曼谷亞運之竟家活動：三星電子贊助策略解析
}

\author{
Cheng Shao-Tung \\ Department of Physical Education, \\ National Taiwan Normal University, TAIWAN
}

\section{程紹同 \\ 國立臺灣師範大學體育系}

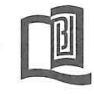
\begin{abstract}
識, 解析其雙贏互利的贊助關係, 做爲彼此未來永續經營之參考借鏡。
\section{前言}

號稱本世紀末亞洲最後一場國際運動賽會 - 曼谷亞運 會, 在歷經政府改組及亞洲金融危機的雙重衝擊下, 險遭 亞洲奧林匹克委員會撤回主辦權的哥運, 所幸有 11 家國際 企業簽下價值約 8,500 萬美元的亞運贊助合約及約 4,160 萬 美元的電視轉播權(註一), 才得以從敗部復活, 順利主辦第 13 屆亞運會。鑑此可知, 企業贊助在大型運動賽會及各級 比賽中, 所扮演之重要關鍵角色。而應用運動贊助之行銷 策略業已成爲廿一世紀企業與運動組織必學的生存之道, 也是一股無法抗拒的行銷新風潮。這是企業保持競争優勢 並超越對手的最佳利器。成功的互動關係更可爲企業與運 動雙方共創多贏互利之亮麗遠景(程紹同, 1998a)。
\end{abstract}

Abstract

The purpose of this paper is to analyze the successful sport sponsorship strategy applied by Samsung Electronics, the first official partner of the $13^{\text {th }}$ Bangkok Asian Games, in 1998. By introducing the integration of sports and corporations, the win-win sponsorship can be discussed and learned by both parties for the long-term development in the next millennium.

\section{摘要}

本文目的旨在探討1998年第13屆曼谷亞運贊助商韓國三星電子集團之成功贊助策略。欲藉對運動與企業合作契機的認

\section{運動的贊助潛力}

國際奧委會主席阵瑪蘭奇 (J.A. Samaranch)曾表示： 「運動是人類在本世紀發展中, 最重要的社會現象之一。不 僅存在於地球村的每個角落且深入人們日常生活之中, 它 的影響力將延至新的紀元」(Thoma \& Chalip, 1996, p. 11)。運動賽會猶如一顆聚光的紫水晶, 可匯集八方現代之 光能而折射出色彩繽紛的亮麗光芒(程紹同, 1998b)。透過 運動員在競技場上追求極致表現的活動, 結合科技、經 濟、政治、文化、藝術等人類智慧精華與力量, 捔手共同
追求眞善美理想之實現。在進入公元 2000 年的前夕, 大型 運動賽會已闡明其本身的時代意義與價値。

運動與企業的合作爲時代所趨。企業藉贊助活動與運 動的結合, 更是天造地設的絕妙拍檔。運動組織藉贊助資 源之取得, 實現推展運動之目標。而企業則藉贊助活動達 成其本身行銷目標。這是完美的雙贏組合。運動爲何是全 球企業的最佳代言人?理由如下：

\section{1. 運動具有大小道吃市場特質}

運動與企業特質性相似, 國際化、多國性。人們對運 動之喜好, 是不分種族、文化、階級、年齡與性別的。可 以跨越國界及語言鸿溝障礙。以今年6-7月間法國世界杯足 球賽單日最高點閱率 (Hit Rate)7000 萬次 (邱潜憓, 1998) 爲例, 可見運動賽會之熾熱程度。對企業而言, 代表著無 限廣大市場潛力。

\section{2. 運動是媒體寵兒，廣告效益無遠弗屆}

以本屆亞運爲例, 媒體工作人員約有7000名前來曼谷 報導這場跨世紀的運動賽會。預估全球電視觀賞人口爲 30 億人次(詿二)。這正是廣告宣傳突顯形象之大好時機。 


\section{3. 運動贊助為企業行銷之新䞟勢}

繼1984年美國洛杉磯奧運會成功運用贊助策略之後， 全球企業投注於運動贊助案例之成長幅度相當驚人。自 1983-1988 年便達到 500\%，接著 1989年的30\%，1991 年的 $11 \% ， 1992-1994$ 年的 17\%，以及 1998 年的 15\% (Stot1ar, 1993；IEG，1994；IEG，1998）。足以證明運動贊助 時代的正式來臨。大型運動賽會不僅是國際矚目的大事件 (big event), 更已成爲企業争奇鬥叟的競技場。在產品差 異愈趨縮小又充滿高度競爭壓力的渾沌國際市場, 運動贊 助策略之應用, 實現了企業強化形象、接觸目標對象、壟 斷市場及成霛良好企業公民等行銷目標之理想。

\section{創造赢家活動的贊助策略}

「運動贊助不單是在競賽場上掛起廠商的廣告布條, 也 不僅限於大會手冊中的感謝對象而已。運動贊助是一種企 業與消費者共舞且創造商機的行銷策略」( 程紹同, 1998a）。IBM 結束與國際奧會長達近 40 年的合作關係, 退 出全球奧運第 4 代贊助計畫 ( T O P 4), 頗值得深思探討 (Narisetti，1998)。贊助活動是結合企業行銷目的的交換 (exchanging) 行爲, 企業本身應把握贊助機會, 詳細規劃整 體行銷計劃, 以擴大贊助宏效。而運動賽會主辦單位更應 策劃具專業與創意的贊助方案及誘人條件, 在符合籌備會 的主辦精神下, 與贊助廠商共同合作, 㩦手創造贏家活 動。韓國三星電子集團(Samsung E1ectronics)深諳箇中精 髓, 爲此次亞運贊助商中最成功的典範 (表一)。本文將 解析該企業之贊助策略, 提供未來執行者之參考。

表一、曼谷亞運贊助商一覽表

贊助商:

宏斯電腦(Acer) 丹雾嘉士伯啤酒 (Car1sberg)

加德士石油(Ca1tex) 富士全錄(Fuji Xerox)

泰國 Laem Thong 銀行寶礦力水得運動創料(Pocari Sweat)

泰國 Samart 電話韓國三星(Samsung)電子

瑞士錶(Swiss Timing) 泰國航空(Thai Airway Internationa1)

豐田汽車( Toyota Motor)

供應商：柯達軟片(Kodak) 代理商：FBT 泰國運動用品

媒體夥件 :

時代雜誌(Time Inc.) 泰國Kantana 樂團

資料來源： http://www.asiagames. th/about/officepart.htm1

\section{三星電子亞運贊助策略分析}

\section{一、企業簡介}

韓國三星電子集團創於 1938年。1940-1950年代, 在 韓國經濟莭困之際, 扮演戰後䋧和與重整國家經濟之重要
角色。1980 年代開始進入牛導體及其他高科技產業。自 1990 年初起，跨入國際經營模式。三星電子全球據點分布 於世界50餘國(如中、美、英、日、新加坡、印尼、印度、 蘇俄、匈牙利、巴西等國家)。擁有25個生產中心、28個 海外分公司以及28個國際銷售子公司。預計公元2000年將 陸續在12個國家建立24個生產基地。主要產品包括資訊與 通訊、電腦、公司自動化、太空科技、家電產品等。其經 營哲學爲專注於人力資源與科技之開發，爲更美好的地球 村而努力 ("Devoting our human resources and technology to the development of better g1obal society")。 而該企業之價值觀則爲人(people)、科技( technology)及未 來(future)。這些理念不僅深植在每一位員工心中, 亦反映 在運動贊助活動之上。期透過運動的力量, 超越性別、國 家、宗教幫助人類相互瞭解, 以追求和平與快樂。爲此, 三星亦將運動競爭的眞義帶入日常工作中, 學習追求卓越 之精神(註三)。

\section{二、運動贊助理念}

根據該企業副總裁 I1-Hyung 表示：「運動贊助是三星 經營理念與行銷策略的一部份。尤其在奥運贊助的參與方 面, 是三星全體員工及韓國人的榮耀。更代表著全世界對 韓國企業暨國家卓越表現的讚賞與肯定」(註四)。三星希望 藉由持續的運動贊助及贊助頭銜, 強力全面開啓韓國暨亞 洲市場的廣告宣傳活動。該公司認爲贊助亞運有助於三星 電子主要產品在泛亞地區的宣傳。亞洲人口( 30 億)佔全球 的五分之三且爲成長最快速的世界市場。贊助亞運爲三星 電子整體促銷計畫及䇺定市場競争優勢之最佳觸媒。

\section{三、恶運贊助協識}

曼谷亞運篇首屆採用奧運贊助模式的亞運會, 即贊助 權利範圍涵蓋全泛亞地區。不僅贊助商地位提昇且分爲官 方夥伴(official partner)、官方贊助商(official sponsor) 以及官方供應商( official supplier)等三級。而三星電子 雼第一家與曼谷亞運籌備會 (BAGOC) 簽下贊助合約的官方夥 伴, 提供 9 百萬美元現金以及大會所需之電子產品(註五)。 其享有之贊助特權包括 : (1)電視、音響及家電產品贊助頭 銜(含銷售活動權利)，(2)成爲下屆亞運贊助商之優先選擇 權(對於日本所長期把持的亞洲市場而言, 無疑提供三星電 子突破「日本防線」的絕佳良機）（如表二）。

\section{表二、亞運贊助權㿽}

1. 可使用本屆亞運官方標誌及贊助頭銜。

2. 可在各比賽場地外邊界區進行廣告宣傳活動。

3. 可在各比賽場地進行各式平面宣傳活動(printed materials)。

4. 可分發產品促銷用途(product promotion)之免費試用品。

5. 可在各比賽場地展示、銷售產品並服務大衆。

資料來源:

(http://sports.samsung.com/english/bangkok/passage/index-1.html) 


\section{四、贊助策略分析}

運動的特性之一, 嵈[不確定性」(inconsistency)。意 指比賽勝負無法事先預知, 且運動賽會之成敗亦有不可預 測的變數（如1996 年美國亞特蘭大奧運的爆炸案）。因此， 贊助商爲確保其贊助效益, 則必須全力促成大會之圓満順 利, 才是企業贊助成功的唯一保証。如同 1996年美國亞特 蘭大奧運全球贊助廠商－可口可樂(Coca-Cola) 之行銷策略 「一切爲運動迷」(For the Fans), 三星規劃一系列行銷 活動來支持亞運的舉辦。

窟把握 15 天短暫會期活動時效 (12月 6-20日), 以及 擴大亞運宣傳效果。三星在亞運前 100 天即全面展開其贊助 活動。首先登場的是「與您同跑」活動(Let's Run Together), 此項活動同時在泰國曼谷、中國北京及印度新 德里三地舉行。一方面絾亞運盛會熱身並且爲該國亞運選 手募款加油。該項活動之進行均由當地三星電子公司與該 國奧會或全國運動組織共同舉辦。參加對象不分性別、年 齡、國籍、運動能力等條件。凡報名參加者均可獲得印有 紅、黃、綠色星狀標識之路跑大會象徵的免費T恤一件, 以 及可參加摸彩獎活動。大會提供三星產品, 包括頭獎彩色 電影機等家電用品及亞運門票等豐富獎項。另外, 凡跑完 全程5公里的參加者, 三星皆捐出美金 1 元作䍃運動基金, 以表示支持該國的運動發展及運動員(如泰國業餘運動協會 即獲得 10,000 美元的捐助）。此項路跑活動的口號爲「爲 亞洲共跑」(Let's Run for Asia)。繼 1995 年三星在匈 牙利成功舉辦年度路跑活動(Samsung Running Festiva1)， 使其成爲跨越中歐最大型的公開運動慶典活動之一(200,000 人參加)之後, 「與您同跑」活動更成功地揭開曼谷亞運的 序幕, 亦促進全亞洲人民之間的情感與友誼。三星計劃每 年舉辦類似活動, 以延續這項成果(註六)。

接著進行的是「最有價値運動員」(NVP Award)的表彰 活動、韓國 Suwon 市立交響樂團的巡迴演出、亞運會場區 「韓國街」的設立以及三星各亞運會場據點的服務與贈品活 動等。這些不僅輝映出本屆亞運「友誼無國界」(Friendship beyond Frontiers）的精神, 也實現了三星贊助目標。 即是藉與亞運的知名度和追求卓越的運動榮耀之結合, 強 化本身國際品牌形象及知名度, 超越企業競争對手, 提昇 亞洲市場佔有率及產品銷售量, 並且增加三星員工的向心 力及榮譽感(䧏七)。

\section{結語}

運動與企業的共通點是跨國性的! 是全球化的! 在景氣 低迷的亞洲國際市場之中, 韓國三星電子集團獨具慧眼地 持續其贊助策略(註八), 成鹞2000年雪梨奧運的贊助商, 長期性地規劃其運動行銷計劃。在亞太地區企業贊助市場 (33億美元) (IEG, 1998)快速擴展之際, 三星穞健地跨出示範 的一步之同時, 其他亞洲國際企業是否能有遠見, 來開啓
這扇跨世紀的希望之門呢?而面對此一未來發展, 運動經理 人筧領導者又是否能掌握搊勢, 引領運動組織永續經營?

\section{敦解}

䧏一: http://cnnsi.com/o1ympics/news/1998/08/28/asia. games/

註二: http://ww2.asiangames.th/news/main-info.htm1

註三: http://samsung.com/english/news/index.htm1

註四: http://sports. samsung. com/eng1ish/news/index.htm1

註五: http://sports. samsung. com/eng1ish/bangkok/index2-8.htm1

註六: http://sports. samsung. com/eng1ish/bangkok/index3.htm1

註七: http://sports. samsung. com/eng1ish/bangkok/index2-2.htm1

註八: 三星電子持續進行的運動贊助活動, 其中除 1994 年日 本廣島亞運及贊助亞洲地區一些足球隊外, 在國際間, 三星贊助 18 支海外職業運動團隊；8 項圭要運動競賽 （如三星國際杯、馬術大賽、Copa Cup 庈拉丁美洲足 球錦標賽等)。在韓國本土, 三星電子名列全國最佳運 動贊助廠商, 贊助項目遍佈籃球、足球、棒球、桌球等 各種運動。(http://sports. samsung. com/eng1ish/ sports/index.htm1)

\section{參考文獻}

邱㴡憓 (1998, August) 資訊業者撒「網」捕魚。廣告雜誌。 87 期, 頁 44-47。

程紹同 (1998a) 運動贊助策略學。台北：漢文書店。

程紹同 (1998b, December) 亞洲風暴下的曼谷亞運會: 運動 行銷開創新紀元。廣告雜誌。92 期, 頁 61-63。

International Events Group (1994, May 18). Assertions, Sponsorship Report, p. 2.

International Events Group (1998, January 11). Sponsorship Report, p. 1 .

Narisetti, R. (1998, August 7). IBM is ending Olympic deal in cost dispute. Wall Street Journal, p. B1.

Stotlar, D. K. (1993). Successful sport marketing. Dubuque, IA: Wm. C. Brown Communications, Inc.

Thoma, J. E. \& Chalip, L. (1996). Sport governance in the global community. Morgantown, WV: Fitness Information Technology, Inc. 